\title{
Food for thought on the GMO debate
}

\author{
Kimberly Brooks
}

Genetically Modified Organisms in Agriculture: Economics and Politics Edited by Gerald C. Nelson

Academic Press; \$69.95, 344 pp, hardcover ISBN 0125154224, 2001

Brave is the editor who is up to the challenge of producing a textbook that covers the many complex and controversial social, political, and economic issues generated by the current "hot potato"-agricultural biotechnology. Tackling the dearth of economic and scientific certainties associated with the field in a form that is accessible to novice and expert alike is no easy task. However, Gerald Nelson has managed admirably to achieve this in Genetically Modified Organisms in Agriculture: Economics and Politics, a collection of papers prepared by leading voices in the ongoing debate about genetically modified organisms (GMO).

Nelson sets the scene by focusing on something the GMO debate desperately needs-hard facts. Opening with cogent economic analyses, Nelson and several colleagues from the University of IllinoisUrbana provide preliminary thoughts on the tough questions that have gone unanswered since the early 1990s: Who are the winners and the losers from adoption of this technology? Will farmers really experience a fiscal benefit when they use GM crops? And how much do firms actually stand to gain from current patent and intellectual property laws?

The first half of Part I provides the beginnings of a quantitative analysis of the market for GMOs, whereas subsequent chapters provide a more qualitative picture of non-market effects such as regulatory concerns, the potential environmental

Kimberly Brooks is Assistant Director of Communications at the Pew Initiative on Food and Biotechnology (Washington, DC; kbrooks@pewagbiotech.org). impact of GMOs, and how markets respond to consumer demand. However, although the later chapters of Part I attempt to provide an objective look at the risks and benefits of agricultural biotechnology, the reader is left with the impression that the benefits far outweigh the risks-a conclusion which several players in the debate might dispute.

Veterans of the global debate about GMOs know that credible research into its ecoGenetically Modified Organisms in Agriculture Economics and Politics nomics and long-term environmental impact are vital for the future of the technology. However, they also know that whichever stakeholder first ventures into such contentious arenas will likely inspire disgruntled opponents to conduct comparable studies and derive results to support their own ideology or agenda. By presenting economic analyses that are more supportive than critical of the technology, Nelson throws down a gauntlet for all stakeholders, inspiring them to fill the void of economic fact on this issue.

After providing food for thought about the supply and demand of GMOs, Nelson next turns to the overarching issue of politics in Part II. Rather than showcase all viewpoints, Nelson has sought to illuminate the polarization between the global and US domestic debate. A paper by Julie Babinard of the International Food Policy Research Institute (IFPRI; Washington, DC) and Timothy Josling from the Institute for International Studies, Stanford University (Stanford, CA) provides readers the political "lay of the land" before representatives from key organizations in the United States and abroadincluding Consumers Union, Grocery Manufacturers of America, several academic institutions, the European Commission, the US Congress, and Monsanto-present their particular perspectives.

The arguments presented in Part II clearly highlight that the opinions of the different stakeholders are not diametrically opposed, but differ often by subtle shades. Per Pinstrup-Andersen and Marc Cohen, both of the IFPRI, argue that agricultural biotechnology is essential to food security, allowing developing countries to meet their own supply needs, and become selfsustaining. Dennis Avery of the Hudson Institute (Indianapolis, IN) argues that biotechnology is needed to feed the expected population boom, and for its potential benefits for other plant life such as trees. However, Vandava Shiva from the Research Foundation for Science, Technology and Ecology in New Delhi, India, calls for a 5year moratorium on all field testing of GMOs on the grounds that industry has erroneously sped-up adoption of GMOs before their environmental impacts have been assessed. Richard Caplan from US Public Interest Research Group insists that the regulatory framework for GM crops is too unpredictable and risky for their widespread use. Collectively, the papers capture the complexity of the arguments so frequently aired in favor or opposition of agricultural biotechnology.

The final section of the book examines the issues fundamental to the debate-but perhaps in too little extent. Indeed, only 30 pages of this 300-page book examine the "nuts and bolts"- the history of agricultural biotechnology, the intricacies of genetic engineering, the scientific studies of the effects of GMOs (e.g., the impact of $B t$ corn on monarch butterflies). This gap is unfortunate because an in-depth discussion of topics, such as regulatory gaps and reform possibilities, would certainly be valued by sophisticated readers looking for more indepth coverage of the key issues.

To date, most discussions about agricultural biotechnology in the United States have taken place among an elite circle of stakeholders, scientists, academics, and policymakers. However, most consumers do not know enough about the issue to evaluate genetic engineering and make informed decisions. Although some basic topics might have benefited from more indepth coverage, Nelson should be commended for bringing together the many voices in the debate. Genetically Modified Organisms in Agriculture: Economics and Politics is a useful guide for novices to the field and perhaps could be used as a general reference for those already familiar with the intricacies of this topic. 